\title{
Innovation Teaching Practice Based on Collaborative Tabu Optimization under the Network
}

\author{
Zhichao Zhao, Tiefeng Wu ${ }^{*}$ \\ School of Information \& Electronic Technology, Jiamusi University, Jiamusi, China \\ *Corresponding author
}

Keywords: collaborative taboo optimization; innovative education; network distribution; innovative learning

\begin{abstract}
The innovative education is based on the development of innovative thinking and the training of innovative talents as the basic value orientation. It is necessary to recognize the problems encountered in innovative education, explore new ways and methods of innovative education with new ideas, and strive to implement innovative education in teaching. Tabu search algorithm is a combined optimization algorithm and an extension of local search algorithm. It is a successful application of artificial intelligence in combinatorial optimization algorithm, which is characterized by the use of tabu techniques. The taboo in the real sense is the prohibition of duplication of the previous work. Tabu search algorithm uses a tabu table to record the local best points which have arrived. In the next search, tabu list information is used to search these points no longer or selectively. In the course of teaching, the students' innovative ability is constantly improved so the comprehensive learning ability of the students will be improved.
\end{abstract}

\section{Introduction}

For a long time, China education has been influenced by the "exam oriented" teaching mode, classroom education often "cramming" and "base", students learn passively and burden, make it become a step of memory machine. Therefore, there are often a lot of high scores and low energy type "talents". In comparison with Western students, the creative ability of Chinese students is often low. As Neil Postman, a famous educationalist, criticized, "when children enter school, they are like" question marks ", but when they graduate, they are like a 'stop number', which can only be a failure of school education. Teaching work must also conform to the requirements of the times, build a new model and explore new ways. The classroom teaching of primary and middle school students needs innovation. Comrade Jiang Zemin pointed out that "innovation is the soul of a nation and the inexhaustible motive force for the prosperity of a country". The times are developing and the situation is changing. The development of teaching is showing new characteristics. Classroom teaching should also adapt to the new social needs. While inheriting the experience and achievements of past classroom teaching, it is good at innovating and strengthening innovation. Therefore, in order to cultivate innovative education with innovative thinking ability, it has become a top priority.

\section{The Basic Connotation of Innovation Education and Its Role in Teaching}

The so-called innovation education is a kind of educational activity that the main body trains the students to have a strong sense of innovation, spirit of innovation and the ability of innovation. Through the cultivation of innovative consciousness, students can fully understand the importance of innovative education, so as to stimulate their enthusiasm and interest in innovation, and enhance their sense of urgency and responsibility for innovation. The spirit of innovation is to cultivate students' spirit of exploration, knowledge, invention and innovation, including curiosity and sensitivity to surrounding things, and persistent pursuit of truth. Innovation ability mainly includes two aspects of innovative thinking ability and practical ability, creative thinking ability training is to 
cultivate students' ability of finding and solving problems, namely through the cultivation of imagination and logical thinking ability of the students to enrich, find out problems in the practical work, and to find out the way to solve the problem. The creative education is to inspire the creative motivation of the students, encourage the students to create the creative performance, so as to promote the development of creative talent. As far as its connotation is concerned, it is a teaching mode for teachers to stimulate and increase the creative behavior of the students through the content of the curriculum and the planned teaching activities.

\section{Cooperative Tabu Algorithm}

The two main indicators in the taboo table are taboo objects and tabu lengths. In tabu algorithm, because we have to avoid duplication of operations, we need to put some elements in tabu list to prohibit operation of these elements, which are taboo objects we refer to. The tabu length is the number of iterations that are not allowed to be selected by the banned object. The general is to ban a number of $\mathrm{X}$ objects ( $\mathrm{T}$, tabu length) requires that the object $\mathrm{x}$ is banned in $\mathrm{t}$ iteration, using tabu in the tabu list $(\mathrm{x})=\mathrm{t}$ memory, each iteration step, the indexes of operation tabu (x) $=\mathrm{t}-\operatorname{tabu}(\mathrm{x}) 1$, until $=0$ the lifting of the ban. As a result, we can divide all the elements into two classes, the forbidden element and the free element. Tabu length selection of $t$ can have a variety of methods, such as $t=$ or $t=[n *]$, constant, where $n$ is the number of neighbors in the neighborhood; this rule is easy to be realized in the algorithm.

The evaluation function is an evaluation formula of the selection of the candidate collection elements, and the elements of the candidate set are selected by the evaluation function value. It is easier to understand the objective function as an evaluation function. The target value is a very intuitive index, but sometimes, in order to be convenient or easy to calculate, other functions will be used to replace the objective function.

In the iterative process of tabu search algorithm, all objects in the candidate selection will be taboo or an object is banned, but if the ban is lifted, the target value will be greatly reduced. In this case, in order to achieve the global optimal, we will allow some taboo objects to be re - optable. This method is called amnesty, and the corresponding rules are called amnesty rules.

In the process of calculation, it is beneficial to memorize some information to solve the problem. If one of the best target values appears very high, we have reason to speculate that the existing parameter algorithms may not be able to get better solutions. In order to solve the problem, we can remember the frequency of the set, the banned object group, the set of target values, and so on. Frequency information helps to further enhance the efficiency of tabu search. We can dynamically control the length of the taboo according to the frequency information. The frequency of an optimal target value is very high, and there is a reason to terminate the calculation and consider this value as the optimal value.

\section{The Problems Existing in the Current Innovation Education}

At the beginning of 1995, when he was lecturing at the beginning of, Dr. Nobel, a physics prize winner, asked a reporter: "what are the differences between Chinese students and foreign students?" Professor Yang replied: "in foreign countries, Chinese students' academic achievements are excellent. But the Chinese students have little courage, the teacher did not dare to think, the teacher did not do what did not dare to do. A student once said: "if the teacher asks a question, ten Chinese students often answer almost, and foreign students, ten people may be able to tell the twenty answers, although some very strange ideas." Nobel prize winner Chinese American professor Zhu Diwen said: "American students are not as good as Chinese students, but they are innovative and adventurous, so they often create some amazing achievements. The above three scholars have shown the lack of creativity of Chinese students. The lack of creativity of students in China is mainly due to the neglect of the cultivation of students' creativity for a long time in our education, and we can never get rid of the strange circle of one-sided pursuit of higher learning rate and wander in the knowledge based education mode. In this model, knowledge is the only pursuit of the 
students, and creativity is severely strangled. But there are still the following problems in the educational environment of pursuing innovation teaching at present.

\subsection{Students' innovation level is not high}

At present, many schools carry out various innovative education and innovation activities, but the results are often not satisfactory, and they fail to get the desired results. As time passes, teachers and students lose interest. The cause of this phenomenon is mainly the students' knowledge and skills has not reached a sufficient level, students are interested in, but no problem consciousness in innovation activities, the problem is not found, or found a problem, but no professional thinking to solve the problem, not the result, so as to gradually lose interest and motivation innovation.

\subsection{Students are incorrectly understood for the purpose of innovative education}

The innovative education is an important part of quality education, training innovation consciousness, innovation spirit and innovation ability, but a considerable part of the innovation education as schools to carry out extracurricular activities, teachers do not pay attention because the job is busy, the students also think this is just a kind of activities of interest, want to participate in it. Don't want to take part in what no influence; the other part is that innovation is to tangible results, even innovation is to obtain patent in order to obtain enough income. These two kinds of thought for students either in innovative activities is just to take credit, tasted, understand, participate in or even if done, with a strong utilitarian heart, but for ordinary innovative school activities for a contemptuous disregard.

\subsection{Schools are not aware of the significance of innovative education}

At present, many schools are still in the teaching practice of wearing new shoes to walk the old state, try to bring down a, find a "," push revolution "practice teaching" basic knowledge "to There are plenty of people who; in the reform debate still full of ear; changes in the new class more performance a multimedia courseware for teachers to teachers and students of the dazzling" operator "; to respect the students no longer students' mistakes, criticism and so on. Blind innovation inevitably brings more problems. According to the provisions of the new curriculum reform, the purpose of teaching is to promote the coordinated development of students' knowledge and ability, process and method, emotional attitude and values, and promote the all-round development of students. The significance of innovative education in many schools do not know the place, do not give students a discretionary time or do not consider the interests of the students, or the lack of necessary guidance in innovation activities, innovation and education innovation "lively" to go in the form, the results did not achieve the purpose of creative education.

\section{Solutions' Problems in the Current Innovation Education}

Analyzing the causes of these problems, we can conclude the implementation conditions of innovative education into two parts, one is the importance and support of schools, and the other is the understanding and participation of students. Two The importance and support of schools is reflected in that schools should enhance teachers' sense of innovation and innovation, as well as hardware matching and software support for innovative education, so that students' innovative activities can be carried out better. The students' understanding and participation in the school should reflect through the promotion of innovation education, and the students to inform students through participation in innovation activities may be all improved, and guide students to experience and understand the formation of innovation and innovation, innovation consciousness and consciously participate in the habit.

\subsection{Cultivate the habit and attitude of students' Innovation}

According to the students' basic knowledge and professional skills shortage, according to the students' interests and hobbies and different personality traits, combining students' understanding of the purpose of innovation, the school should be through the organization, plan, arrange a series of 
activities in a longer period of time will gradually guide the students, learning, innovation and knowledge of their own interest in training together, doing, learning and thinking learning consciousness and learning habits, to cultivate and improve their own problems, ability to analyze and solve problems, make students realize the significance of innovation and experience to solve the problem of happiness, the formation of innovation habits and attitudes. At the same time, it also guides students to think about their future development.

\subsection{Teachers should strengthen the consciousness and purpose of innovation}

Although the current education is in the form of classroom teaching based on students, but the guiding role of teachers to students is crucial, has a very important significance of innovation activities of teachers to students and teachers through their goal and plan, not only can guide students to explore the problems and develop a sense of innovation, improve the ability to innovate, shorten the innovation period, so that the students can experience more innovation in discovering and analyzing the problems and solve problems, so the teachers themselves should enhance innovation consciousness and innovation consciousness and ability training, students can better. The purpose of education is to cultivate talents to meet the needs of the time, twenty-first Century has constantly innovation ability of high-quality personnel, as the cross century teachers should cultivate students' autonomous learning and innovation focus on quality in teaching, and create a new world of classroom teaching in the new century.

\section{Acknowledgements}

Research project of education and teaching in Jiamusi University, Project number: JYA2011-071, Research on the cultivation of Postgraduates' innovative thinking based on Interdisciplinary; Research project of education and teaching in Jiamusi University, Project number: 2016JL1028, Research on the reform of talent training mode of major disciplines enrollment in Universities.

\section{References}

[1] Malarkodi, M.P., Arunkumar, N., Venkataraman, V. Gabor wavelet based approach for face recognition (2013) International Journal of Applied Engineering Research, 8 (15), pp. 1831-1840.

[2] Stephygraph, L.R., Arunkumar, N. Brain-actuated wireless mobile robot control through an adaptive human-machine interface (2016) Advances in Intelligent Systems and Computing, 397, pp. 537-549.

[3] Weisen Pan, Shizhan Chen, Zhiyong Feng. Investigating the Collaborative Intention and Semantic Structure among Co-occurring Tags using Graph Theory. 2012 International Enterprise Distributed Object Computing Conference, IEEE, Beijing, pp. 190-195.

[4] Arunkumar, N., Jayalalitha, S., Dinesh, S., Venugopal, A., Sekar, D. Sample entropy based ayurvedic pulse diagnosis for diabetics (2012) IEEE-International Conference on Advances in Engineering, Science and Management, ICAESM-2012, art. no. 6215973, pp. 61-62.

[5] Arunkumar, N., Ramkumar, K., Hema, S., Nithya, A., Prakash, P., Kirthika, V. Fuzzy Lyapunov exponent based onset detection of the epileptic seizures (2013) 2013 IEEE Conference on Information and Communication Technologies, ICT 2013, art. no. 6558185, pp. 701-706. 